Coupling of the lactone-ring conformation with crystal symmetry in 6-hydroxy4,4,5,7,8-pentamethyl-3,4-dihydrocoumarin. Erratum

\author{
Armand Budzianowski Andrzej Katrusiak, \\ Faculty of Chemistry, Adam Mickiewicz University, 60-780 Poznań, Grunwaldzka 6 , \\ 60-780 Poznan, Poland
}

In the paper by Budzianowski \& Katrusiak (2002) Acta Cryst. (2002), B58, 125-133 Figs. 5 and 8 on pages 131 and 132 were transposed while adjusting colour details indicated by the authors in the proof. Revised PDF versions of these pages are available in the online version of this erratum, which is available through Crystallography Journals Online.

\section{Two fluoradene derivatives: pseudosym- metry, eccentric ellipsoids and a phase transition. Erratum}

\section{Aibing Xia, John P. Selegue, Alberto Carrillo, Brian O. Patrick, Sean Parkin and Carolyn Pratt Brock*}

Department of Chemistry, University of Kentucky, Lexington, KY 40506-0055, USA

Numerous printing errors in the paper by Xia et al. [Acta Cryst. (2001), B57, 507-516] are corrected.

In the paper by Xia et al. (2001) a number of special characters $\left({ }^{\prime}, \lambda\right.$, $\AA, \sigma, \Delta, \ddot{o})$ were omitted in the printed and PDF versions of the article; the HTML version, however, was correct. The corrected version of the paper is now available from Crystallography Journals Online.

\section{References}

Xia, A., Selegue, J. P., Carrillo, A., Patrick, B. O., Parkin, S. \& Brock, C. P. (2001). Acta Cryst. B57, 507-516.

\section{Group-Theoretical Analysis of Octahe- dral Tilting in Perovskites. Erratum}

\author{
Christopher J. Howard ${ }^{\mathrm{a} *}$ and Harold T. Stokes ${ }^{\mathrm{b}}$
}

aAustralian Nuclear Science and Technology Organisation, Private Mail Bag 1, Menai NSW 2234, Australia, and ${ }^{\mathbf{b}}$ Department of Physics and Astronomy, Brigham Young University, Provo, Utah 84602-4675, USA

An error has been noted within Fig. 1 of the paper by Howard \& Stokes (1998). There is a group-subgroup relationship between $I 4 / m c m\left(a^{0} a^{0} c^{-}\right)$and $C 2 / c\left(a^{-} b^{-} b^{-}\right)$, and this should be indicated on the figure by a continuous line joining the corresponding boxes. The corrected version of the figure is shown here.

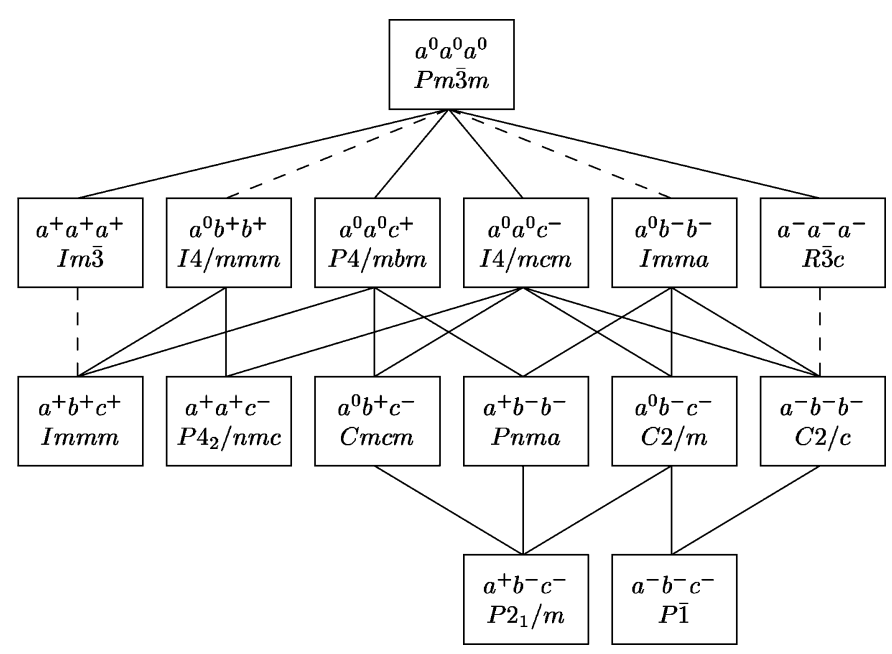

Figure 1

A schematic diagram indicating the group-subgroup relationships among the 15 space groups tabulated by Howard \& Stokes (1998). A dashed line joining a group with its subgroup indicates that the corresponding phase transition is required by Landau theory to be first order.

\section{References}

Howard, C. J. \& Stokes, H. T. (1998). Acta Cryst. B54, 782-789. 